\title{
ANALISA KEKUATAN POTONG DAN PEMILIHAN BAHAN UNTUK TYPE CUTTER MACHINE AX-105U-N-282A, KAPASITAS TANGKI 50 L DAN TEKANAN 16 Mpa
}

\author{
RUSLAN DALIMUNTHE \\ Universitas Sang Bumi Ruwa Jurai \\ ruslandalimunthe@gmail.com
}

\begin{abstract}
Analisa kekuatan potong dan pemilihan bahan untuk Type Cutter Machine perlu diperhatikan untuk mengikuti era teknologi industri yang berkembang sangat pesat ini. Disebabkan oleh banyaknya industri yang menggunakan mesin dengan sistem kontrol numerik yang memiliki keunggulan dalam membawa massa suatu produk dengan daya saing penuh di dunia industri. Spesifikasi mesin yang dianalisa sebagai berikut: Hidrolik set (power pack): Yuken, Tipe AX-105U-N-282A, Pump 10L/min, Kapasitas tangki 50 l, Tekanan 16 Mpa, Cylinder: Yuken, Tipe CJT 35-FA 160 B-400, dan Tekanan $140 \mathrm{Kg} / \mathrm{cm}^{2}$. Hasil penelitian sebagai berikut: a. Besarnya tekanan yang terjadi pada silinder adalah sama dengan kondisi aktual mesin yaitu sebesar $14 \mathrm{~kg} / \mathrm{cm}^{2}=13,95$ bar. b. Besarnya volume yang dibutuhkan pada saat terjadinya proses pemotongan sebesar 10,32 l. Sedangkan kapasita tangki pada hydraulic power pack sebesar $50 \mathrm{l}$. c. Pemotong ban menggunakan mesin hidrolik dengan spesifikasi set hidrolik atau power pack Yuken kapasitas tangki 50L, tekanan 16 Mpa. Sedangkan silinder dengan spesifikasi silinder tipe yuken CJT 35-FA-160 B-400.
\end{abstract}

\section{Abstract}

Analysis of cutting strength and selection of materials for Type Cutter Machine should be considered to follow the era of industrial technology is growing very rapidly. Due to the many industries that use machines with numerical control systems that have the advantage in bringing the mass of a product with full competitiveness in the industrial world. Engine specifications are analyzed as follows: Hydraulic set (power pack): Yuken, Type AX-105U-N-282A, Pump 10L / min, Tank Capacity $50 \mathrm{l}$, Pressure 16 Mpa, Cylinder: Yuken, Type CJT 35-FA 160 B - 400, and Pressure $140 \mathrm{Kg} /$ $\mathrm{cm}^{2}$. The results of research as follows: a. The amount of pressure that occurs on the cylinder is the same as the actual condition of the machine that is equal to $14 \mathrm{~kg} / \mathrm{cm}^{2}=13.95 \mathrm{bar}$. $\mathrm{b}$. The amount of volume required at the time of 
the cutting process of 10.32 l. While the tank capacities on hydraulic power pack of $50 \mathrm{l}$. c. Tire cutters use hydraulic machines with hydraulic set specifications or Yuken power pack tank capacity of 50L, pressure $16 \mathrm{Mpa}$. While the cylinder with crane type specifications CJT 35-FA-160 B-400.

Keywords : cutting force, material selection, Type Cutter Machine, Hydraulic set (power pack): Yuken

\section{PENDAHULUAN}

\subsection{Latar Belakang}

Analisa kekuatan potong dan pemilihan bahan untuk Type Cutter Machine perlu diperhatikan untuk mengikuti era teknologi industri yang berkembang sangat pesat ini. Disebabkan oleh banyaknya industri yang menggunakan mesin dengan sistem kontrol numerik yang memiliki keunggulan dalam membawa massa suatu produk dengan daya saing penuh di dunia industri.

Mesin yang digunakan dalam proses pembuatan ban salah satunya adalah Tyre cutter machine. Berbagai macam dan jenis dari type tyre cutter machine. Mesin tyre cutter ini terdapat pada bagian laboratorium yang digunakan untuk memotong ban yang kemudian hasil dari potongan tersebut dipakai untuk penelitian komponen-komponen yang ada dalam ban tersebut. Mulai dari tapak ban, ply, nyon, bead dan lain-lain. Dengan penelitian ini didapat komposisi untuk membuat ban yang siap untuk dipasarkan sesuai dengan yang dibutuhkan oleh konsumen.

Selain dari pemilihan bahan, adanya berbagai macam faktor penyebab terjadinya keausan pada pisau atau cutter tersebut. Diantaranya tebal dari ban yang hendak dipotong, besarnya tenaga yang dikeluarkan saat memotong ban 
juga mempengaruhi terjadinya keausan pada pisau dan pemeliharaan atau maintence dari mesin tersebut juga mempengaruhi terjadinya keausan.

\subsection{Perumusan Masalah}

"Bagaimana menganalisa besarnya tenaga yang digunakan saat pemotongan, pemilihan bahan yang pas untuk digunakan membuat cutter, serta faktorfaktor penyebab terjadinya kerusakan atau keausan pada pisau".

\subsection{Tujuan Penelitian}

Adapun tujuan dari penelitian ini adalah:

1. Menghitung besarnya kekuatan pada saat proses pemotongan

2. Mengetahui bahan yang pas digunakan untuk cutter

3. Mengetahui faktor-faktor penyebab terjadinya keausan pada cutter

4. Membandingkan hasil perhitungan teoritis dengan kondisi actual

\section{LANDASAN TEORI}

Karakteristik antara ban radial dan biasa tire pada Tabel 1 di bawah ini:

Tabel 1. Karakteristik antara Ban Radial dan Biasa Tire

\begin{tabular}{l|c|c}
\hline \multicolumn{1}{c|}{ ITEM } & RADIAL & BIAS \\
\hline Wear resistance/mileage & Good & Less \\
\hline Heat generation/build up & Low & Less \\
\hline Handlinh Stability & Good & Greather \\
\hline Rolling Resistance & Low & Less \\
\hline Driving \& Beaking Performance & Better & Easy \\
\hline Riding Comfort & Hard to envelope & Easy \\
\hline Steering wheel manipulation & Heavy at low speed & High \\
\hline High Speed Performance & High & Less \\
\hline Fuel comsumtion & Low & Murah \\
\hline Cornerring control & Good & Low \\
\hline Harga jual & Mahal & Murah \\
\hline Accuracy m/c building & High & Mahal \\
\hline Harga m/c building & &
\end{tabular}




\section{PERBEDAAN ANTARA TUBE TYPE DAN TUBELESS}

Keunggulan dan kelemahan antara ban tubeless dan ban biasa tyre pada Tabel 2 di bawah ini:

Tabel 2. Keunggulan dan Kelemahan antara Ban Tubeless dan Biasa Tyre

\begin{tabular}{|c|c|c|}
\hline ITEM & $\begin{array}{c}\text { TUBELESS } \\
\end{array}$ & TUBE TYPE \\
\hline \multirow{3}{*}{ Keunggulan } & $\begin{array}{l}\text { Bila ban terkena paku, ban tidak akan } \\
\text { langsung kempis tetapi angin akan } \\
\text { keluar secara perlahan walaupun pada } \\
\text { akhirnya akan tetap kempis juga. }\end{array}$ & $\begin{array}{l}\text { Harga ban lebih murah ketimbang } \\
\text { ban tubeless }\end{array}$ \\
\hline & $\begin{array}{l}\text { Ban tubeless bisa diisi dengan angin } \\
\text { Nitrogen, angin Nitrogen sangat } \\
\text { berguna untuk mendinginkan ban } \\
\text { (sifatnya dingin). }\end{array}$ & $\begin{array}{l}\text { Biaya tambal lebih murah } \\
\text { ketimbang ban tubeless }\end{array}$ \\
\hline & Tidak menggunakan ban dalam & $\begin{array}{l}\text { Bisa memakai velg jenis apa saja } \\
\text { asalkan masih velg motor }\end{array}$ \\
\hline \multirow[b]{2}{*}{ Kekurangan } & $\begin{array}{l}\text { Harga ban yang lebih mahal daripada } \\
\text { ban bias }\end{array}$ & $\begin{array}{l}\text { Jika tertancap paku ban akan } \\
\text { lansung pecah }\end{array}$ \\
\hline & $\begin{array}{l}\text { Tidak bisa mengunakan velg yang } \\
\text { direkomendasikan }\end{array}$ & $\begin{array}{l}\text { Tidak dapat menggunakan gas } \\
\text { Nitrogen }\end{array}$ \\
\hline
\end{tabular}

\section{METODOLOGI PENELITIAN}

\subsection{Obsevasi}

Dalam penulisan ini pengumpulan data dengan cara pendekaatan secara langsung (survey) yaitu pendekatan yang dilakukan dengan cara pengamatan secara langsung untuk melihat kenyataan yang ada mengenai mesin tyre cutting.

Berdasarkan pengamatan yang di dapat dari pengamatan di lapangan adalah mesin tyre cutter ini dapat memotong ban segala ukuran. Mesin ini khusus untuk memotong ban tipe bias (menggunakan ban dalam bukan tubeless). Selain itu adanya banyak faktor yang menyebabkan keausan dari cutter tersebut. 


\subsection{Pengumpulan Data}

Untuk melakukan penelitian, maka dilakukan pengumpulan data, baik itu primer maupun sekunder. Data yang dibutuhkan untuk analisa ini dapat diperoleh dengan pengamatan secara langsung di lapangan.

Metode yang digunakan adalah wawancara, dimana ini penulis lakukan terhadap para pihak yang ada di lingkungan meubel, yang dilakukan dengan mengajukan pertanyaan-pertanyaan secara langsung.

\subsection{Pengolahan Data}

Data yang diperoleh kemudian diolah melalui tahapan-tahapan sebagai berikut:

1) Tahapan Editing

Pada tahap ini data yang terkumpul diseleksi kemudian diambil data yang diperlukan.

2) Tahapan Identifikasi

Data yang terkumpul diidentifikasikan sesuai dengan jenis dan kelompoknya.

3) Tahapan Konstruksi Data

Kemudian data disusun sesuai dengan pokok bahasan dan tujuan penelitian.

\subsection{Mesin Tyre Cutter}

Tyre cutter machine merupakan lmesin yang digunakan untuk memotong ban menjadi bagian kecil untuk diteliti komposisi yang ada pada ban tersebut. Tujuannya untuk mendapatkan komposisi yang ideal sehingga ban tersebt dapat digunakan dengan baik oleh konsumen. Berikut ini spesifikasi dari tyre cutter machine yang digunakan untuk analisis pada penelitian ini. 
Hidrolik set (power pack) : Yuken

Tipe AX-105U-N-282A

Pump $10 \mathrm{~L} / \mathrm{min}$

Kapasitas tangki $50 \mathrm{~L}$

Tekanan $16 \mathrm{Mpa}$

Cylinder

: Yuken

Tipe CJT 35-FA 160 B-400

Tekanan $140 \mathrm{kgf} / \mathrm{cm}^{2}$

\subsection{Analisis Data}

Data yang diperoleh kemudian dianalisis dengan menggunakan metode kuantitatif dan kualitatif. Metode kualitatif adalah metode ang digunakan dengan cara menguraikan data dalam kalimat yang tersusun secara sistematis. Setelah itu data diinterpretasikan atau ditafsirkan sehingga menjadi jelas.

\section{HASIL DAN PEMBAHASAN}

Perhitungan Luas Benda Potong pada Luas Ban Size 12" dan 20" dapat dilihat pada Tabel 3 di bawah ini:

Tabel 3. Luas untuk Ban Size 12" dan 20"

\begin{tabular}{l|l|r|r|c}
\hline No. & \multicolumn{1}{|c|}{ Jenis } & \multicolumn{1}{c|}{$\begin{array}{c}\text { Luasan } \\
\text { Ban Size 12” }\end{array}$} & $\begin{array}{c}\text { Luasan } \\
\text { Ban Size 2" }\end{array}$ & Satuan \\
\hline 1. & a. Luas Wire & 22,7 & 69,5 & $\mathrm{~mm}^{2}$ \\
\hline 2. & b. Luas Karet & 29,5 & 43,3 & $\mathrm{~mm}^{2}$ \\
\hline 3. & c. Luas Tapak & 312,5 & 645,0 & $\mathrm{~mm}^{2}$ \\
\hline 4. & d. Luas Total Karet & 26,38 & 36,8 & $\mathrm{~mm}^{2}$ \\
\hline
\end{tabular}


Tabel 4: Perhitungan Gaya yang Terjadi Pada Saat Pemotongan Ban 12" dan $20 "$

\begin{tabular}{c|l|r|r|c}
\hline No. & \multicolumn{1}{|c|}{ Jenis } & $\begin{array}{c}\text { Luasan } \\
\text { Ban Size 12” }\end{array}$ & $\begin{array}{c}\text { Luasan } \\
\text { Ban Size 2" }\end{array}$ & Satuan \\
\hline 1. & F Wire & $33.376,0$ & $102.217,8$ & $\mathrm{~N}$ \\
\hline 2. & F Karet & $13.187,5$ & $183.895,0$ & $\mathrm{~N}$ \\
\hline 3. & F Total & $46.563,5$ & $286.112,8$ & $\mathrm{~N}$ \\
\hline
\end{tabular}

Tabel 5. Tekanan yang Diperlukan Pada Saat Pemotongan

\begin{tabular}{c|l|r|l}
\hline No. & \multicolumn{1}{|c|}{ Jenis } & Perhitungan & \multicolumn{1}{c}{ Satuan } \\
\hline 1. & P (Tekanan) & 202,4 & Psi \\
\hline 2. & Psi (persamaan 1 Psi) & 0,06894757 & bar \\
\hline 3. & Tekanan yang diperlukan & 13,95 & bar \\
\hline
\end{tabular}

Tabel 6. Volume yang diperlukan saat proses pemotongan

\begin{tabular}{c|l|r|c}
\hline No. & \multicolumn{1}{|c|}{ Volume Silinder } & Perhitungan & Satuan \\
\hline 1. & Saat Maju & 8,04 & $\mathrm{~mm}^{3}$ \\
\hline 2. & Saat Mundur & 2,27 & $\mathrm{~mm}^{3}$ \\
\hline 3. & Total & 10,31 & $\mathrm{~mm}^{3}$ \\
\hline
\end{tabular}

Tabel 7. Pemilihan Bahan Cutter

\begin{tabular}{c|l|r|c}
\hline No. & \multicolumn{1}{|c|}{ Luas Cutter } & Perhitungan & Satuan \\
\hline 1. & Luas Cutter 1 & 5700 & $\mathrm{~mm}^{2}$ \\
\hline 2. & Luas Cutter 2 & 200 & $\mathrm{~mm}^{2}$ \\
\hline 3. & Luas Cutter Total & 5900 & $\mathrm{~mm}^{2}$ \\
\hline
\end{tabular}

\section{Analisa Terhadap Mesin Tire Cutter}

Berdasarkan dari spesifikasi mesin yang didapat dari kondisi mesin aktual maka di dapat data-data sebagai berikut:

Hidrolik set (power pack) :Yuken

Tipe AX-105U-N-282A

Pump 10L/min

Kapasitas tangki $50 l$

Tekanan $16 \mathrm{Mpa}$ 
Cylinder

: Yuken

Tipe CJT 35-FA 160 B-400

Tekanan $140 \mathrm{Kg} / \mathrm{cm}^{2}$

Dari peritungan secara teoritis di dapatkan data sebagai berikut:

a. Tekanan pada Cylinder

Diketahui Asumsi diameter piston adalah $160 \mathrm{~mm}=16 \mathrm{~cm}$

$$
\begin{aligned}
& \mathrm{P}= \\
& \mathrm{F} \text {. } \\
& \mathrm{A}_{\text {silinder }} \\
& =\underline{286112,75 \mathrm{~N}} \\
& \underline{\pi}_{4} \mathrm{x} \mathrm{d}^{2} \\
& =\frac{286112,75 \mathrm{~N}}{\frac{\pi}{4} \times 16^{2} \mathrm{~cm}^{2}} \\
& =142,3 \mathrm{~N} / \mathrm{cm}^{2} \\
& =142,3 \mathrm{~N} \times 0,1 \quad=14,23 \mathrm{~kg} / \mathrm{cm}^{2}
\end{aligned}
$$

Jika konversi $1 \mathrm{~kg} / \mathrm{cm}^{2}=14,22$ Psi (Pound per square inch)

$$
\begin{aligned}
\mathrm{P} & =142,3 \stackrel{\mathrm{kg}}{\mathrm{g}} \times 14,22 \\
& =202,3506 \mathrm{Psi}
\end{aligned}
$$

Jika konversi 1 Psi (Pound per square inch $)=0,06894757$ bar.

Sehingga tekanan yang diperlukan pada saat pemotongan sebesar

$$
\begin{aligned}
\mathrm{P} & =202,3506 \text { Psi } \times 0,06894757 \\
& =13,95 \text { bar }
\end{aligned}
$$

b. Volume Silinder Total

$$
\begin{aligned}
\mathrm{v}_{\mathrm{t}} & =\mathrm{v}_{\text {maju }}+\mathrm{v}_{\text {mundur }} \\
& =8,042 l+2,27 l \\
& =10,32 l
\end{aligned}
$$


c. Debit (Aliran) Fluida

$$
\begin{aligned}
\mathrm{Q} \quad & =\underline{\mathrm{v}} \\
& \mathrm{t} \\
= & 10,32: 1 \mathrm{l} / \text { menit } \\
= & 10,32 \mathrm{l} / \text { menit }
\end{aligned}
$$

\section{KESIMPULAN}

Spesifikasi mesin yang dianalisa sebagai berikut:

Hidrolik set (power pack) :Yuken

Tipe AX-105U-N-282A

Pump 10L/min

Kapasitas tangki $50 l$

Tekanan $16 \mathrm{Mpa}$

Cylinder

: Yuken

Tipe CJT 35-FA 160 B-400

Tekanan $140 \mathrm{Kg} / \mathrm{cm}^{2}$

Dari hasil analisa yang telah dilakukan, maka dapat didapatkan suatu kesimpulan sebagai berikut

Besarnya tekanan yang terjadi pada silinder adalah sama dengan kondisi aktual mesin yaitu sebesar $14 \mathrm{~kg}_{-}=13,95$ bar .

Besarnya volume yang dibutuhkan pada saat terjadinya proses pemotongan sebesar 10,32 $l$. Sedangkan kapasita tangki pada hydraulic power pack sebesar $50 \mathrm{l}$. Maka volume tangki hydraulik power pack lebih dari cukup untuk proses pemotongan. 
Untuk material bahan cutter dari ketiga bahan percobaan untuk cutter, kami lebih memilih menggunakan material SKH 9 bersifat keras, tidak terlalu lunak dan merupakan material yang sering digunakan untuk bahan cutter pada mesin yang lain.

\section{DAFTAR PUSTAKA}

Herman Widodo Soemitro (2012), Mekanika Fluida dan Hidrolika, Erlangga, Jakarta.

Jac Stolk, C Kros (2012), Elemen Mesin (Edisi ke 21), Erlangga, Jakarta.

Khurmi R.S. (2011), A Textbook of Hydraulics, S. Chan \& Clompany Ltd, New Delhi.

Khurmi RS, (2012), Machine Designe, Eurasia Publishing House, PVT Ltd, New Delhi.

MK Dake Jonas (2014), Hidrolika Teknik, Erlangga, Jakarta

Oberg Erik (2012), Machinery's Hanbo $26^{\text {th }}$ Edition for Industry, Industrial Press inc, New York.

Raymond C. Binder (2012), Fluid Mechanics, New Delhi

Sriati Djaprie, George E. Dieter (2012), Metalurgi Mekanik. Erlangga, Jakarta

Sularso, Kyokatsu Suga (2012), Dasar Perencanaan dan Pemilihan Elemen Mesin, PT Pradya Paramitha, Jakarta.

Van Vlack, Lawrence H. (2012), Ilmu dan Teknologi Bahan, Erlangga, Jakarta. 